\title{
Effects of valproic acid and levetiracetam on viability and cell cycle regulatory genes expression in the OVCAR-3 cell line
}

\author{
Patrycja Kwiecińska ${ }^{1}$, Erik Taubø $\|^{2}$, Ewa Ł. Gregoraszczuk ${ }^{1}$ \\ ${ }^{1}$ Department of Physiology and Toxicology of Reproduction, Chair of Animal Physiology, Institute of Zoology, \\ Jagiellonian University, Gronostajowa 9, PL 30-387 Kraków, Poland \\ ${ }^{2}$ Department of Neurology, Division of Surgery and Clinical Neurosciences, Oslo University Hospital - \\ Rikshospitalet and University of Oslo, Norway \\ Correspondence: Patrycja Kwiecińska, e-mail: patrycja.kwiecinska@uj.edu.pl
}

\begin{abstract}
:
Concentration- and time-dependent effects of two antiepileptic drugs (AEDs), levetiracetam (LEV) and valproic acid (VPA), on proliferation, cytotoxicity and expression of cell cycle regulatory genes were investigated in a human ovarian cancer cell line, OVCAR-3. Cells were cultured with VPA or LEV, at concentrations between $100 \mu \mathrm{M}$ and $10 \mathrm{mM}$. Cell proliferation was determined by alamarBlue and BrdU incorporation assays; cytotoxic effects by tetrazolium hydroxide (XTT), acid phosphatase (AP) and lactate dehydrogenase (LDH) assays. Expression of cell cycle regulatory genes was determined by real-time PCR. Exposure to VPA caused a concentration- and time-dependent decrease in cell proliferation (alamarBlue and BrdU incorporation assays), cytotoxic effects above $2.5 \mathrm{mM}$ (XTT and AP assays) and modulated expression of genes primarily responsible for cell cycle arrest in $\mathrm{G}_{1}$ phase. Cell proliferation was unaffected by exposure to LEV for $24 \mathrm{~h}$ and $120 \mathrm{~h}$ (alamarBlue assay), but increased when exposed to LEV for $72 \mathrm{~h}$ and $168 \mathrm{~h}$, at concentrations from $250 \mu \mathrm{M}$ to $1 \mathrm{mM}$. The BrdU incorporation assay showed no effect of LEV on cell proliferation. LEV was cytotoxic at higher concentrations (AP assay), but modulation in expression of cell cycle regulatory genes was not observed. Changes in LDH release were not observed with either AED. In summary, VPA apparently decreased cell proliferation by down-regulating genes responsible for transition from $G_{1}$ to $S$ phase and up-regulating genes responsible for $G_{1}$ phase arrest, which suggest its potential as an anticancer drug. LEV does not exhibit such action.
\end{abstract}

Key words:

valproic acid, levetiracetam, proliferation, cytotoxicity, gene expression, ovarian cancer cell line OVCAR-3

\section{Introduction}

Epithelial ovarian cancer is the most lethal of gynecologic malignancies and current therapeutic regimens for ovarian cancer are largely ineffective in terms of long-term treatment [15]. Thus, development of improved, alternative therapy strategies against ovarian cancer is an important health priority.
It has recently become evident that several antiepileptic drugs (AEDs) are associated with anticancer activity and have influence on cell growth in several cancer cell types in vitro [2]. Valproic acid (VPA) is one of the most frequently prescribed antiepileptic drugs in the world, while levetiracetam (LEV) is a relatively new AED that has been extensively used in recent years [8]. Accumulating evidence indicates 
that VPA is associated with anticancer activity, by inducing differentiation, growth arrest and/or apoptosis in many tumor cells [for review see ref. 3]. Recently, antitumor activity of VPA was also suggested in ovarian cancer cells. Takai et al. [31] showed that VPA causes growth inhibition, cell cycle arrest, apoptosis induction and alterations in the expression of genes in nine ovarian cancer cell lines. Furthermore, VPA has been shown to interact with standard anticancer drugs, resulting in increased inhibition of ovarian cancer development both in vivo [5] and in vitro [19]. To our knowledge, there is one report suggesting antitumor effects of LEV in glioblastoma cells [4]. These authors showed that LEV inhibited cell proliferation and decreased expression of genes and proteins responsible for tumor cell resistance.

Considering these reports, we decided in current study to compare the concentration-dependent and time-dependent effects of VPA and LEV on proliferation, viability and expression of genes important in cell cycle regulation, using a human ovarian cancer cell line, OVCAR-3, as a model system.

\section{Materials and Methods}

\section{Reagents}

RPMI1640 medium without phenol red, fetal bovine serum (FBS, heat inactivated), penicillin/streptomycin solution (penicillin 10,000 units/ml, streptomycin $10 \mathrm{mg} / \mathrm{ml}$ ), phosphate-buffered saline (PBS) and trypsin + EDTA were obtained from Cytogen GmbH (Bienenweg, Germany). VPA was obtained from Sigma Chemical Co. (St. Louis, MO, USA) and dissolved in sterile water. LEV was purchased from UCB Pharma, Belgium (Keppra $100 \mathrm{mg} / \mathrm{ml}{ }^{\circledR}$, for intravenous infusion). The solutions were then further diluted in culture medium.

\section{Cell culture}

The human ovarian epithelial carcinoma cell line, OVCAR-3, was obtained from American Type Culture Collection (Manassas, VA, USA). Cells were routinely cultured in RPMI1640 medium without phenol red, supplemented with $20 \%$ heat-inactivated FBS, $50 \mathrm{IU} / \mathrm{ml}$ of penicillin and $50 \mu \mathrm{g} / \mathrm{ml}$ of streptomycin. The medium was changed every two days. Cells were grown in $75 \mathrm{~cm}^{2}$ culture flasks in a $37^{\circ} \mathrm{C}$ incubator with a humidified mixture of $5 \% \mathrm{CO}_{2}$ and $95 \%$ air. For individual experiments, cells were cultured in RPMI 1640 without phenol red supplemented with 5\% heat inactivated FBS.

\section{AlamarBlue assay}

Long-term cell proliferation was determined using an alamarBlue assay (Invitrogen, Carlsbad, CA, USA). This assay is designed to quantify the proliferation of various human cell lines and is based on detection of the cells' metabolic activity (reduction of resazurin). AlamarBlue has minimal cell toxicity and therefore is appropriate for continuous monitoring of proliferation in the same cell culture at various time points.

Cells were seeded into 96-well culture plates at a density of $1.5 \times 10^{4}$ cells/well and allowed to attach overnight. The next day, the medium was changed and cells were treated with VPA or LEV at concentrations ranging from $100 \mu \mathrm{M}$ to $10 \mathrm{mM}$ for $24,72,120$ and $168 \mathrm{~h}$. Culture medium was used as a control. Medium was changed daily, with new medium and new test compounds added. The alamarBlue stock solution was aseptically added to the wells after 24,72 , 120 and $168 \mathrm{~h}$ of culture, in amounts equal to $10 \%$ of incubation volume. Resazurin reduction was determined after $4 \mathrm{~h}$ incubation by measuring the absorbance at $570 \mathrm{~nm}$ using a fluorescence microplate reader FLx800 (BioTek, Winooski, VT, USA). Six replicates of each sample were run in the same assay.

\section{BrdU incorporation assay}

DNA synthesis in proliferating cells was determined by measuring bromodeoxyuridine (BrdU) incorporation using the commercial Cell Proliferation ELISA System (Roche Molecular Biochemicals, Mannheim, Germany). In this assay, BrdU is incorporated into DNA during $\mathrm{S}$ phase.

Cells were seeded into 96-well culture plates at a density of $1.5 \times 10^{4}$ cells/well and allowed to attach overnight. The next day, the medium was changed and cells were treated with VPA or LEV at concentrations ranging from $100 \mu \mathrm{M}$ to $10 \mathrm{mM}$ for $72 \mathrm{~h}$. Culture medium was used as a control. Medium was changed daily, with new medium and new test compounds added. After $72 \mathrm{~h}$ incubation, the medium was removed and the cells incubated for $3 \mathrm{~h}$ with a BrdU labelling solution (provided with the kit), containing 
$10 \mu \mathrm{M}$ BrdU. The BrdU incorporation assay was performed according to the manufacturer's instructions. Absorbance values were measured at $450 \mathrm{~nm}$ using an absorbance microplate reader ELx808 (BioTek, Winooski, VT, USA). Culture medium alone was used as a control for nonspecific binding. Six replicates of each sample were run in the same assay.

\section{Cytotoxicity assays}

We performed three independent cytotoxicity assays to investigate alterations in metabolic pathways or structural integrity induced by exposure to VPA or LEV.

Cells were seeded into 96 -well culture plates at a density of $1 \times 10^{4}$ cells/well and allowed to attach overnight. After $24 \mathrm{~h}$, the medium was changed and cells were treated with VPA or LEV at concentrations ranging from $100 \mu \mathrm{M}$ to $10 \mathrm{mM}$ for $72 \mathrm{~h}$. Culture medium was used as a control. Medium was changed daily, with new medium and new test compounds added.

\section{XTT cell viability assay}

The XTT sodium salt [2,3-bis(2-methoxy-4-nitro-5sulfophenyl)-2H-tetrazolium-5-carboxanilide inner salt] assay was used to measure the viability of cells. Tetrazolium salts are reduced to formazan by mitochondrial succinate dehydrogenase, an enzyme that is only active in cells with an intact metabolism and respiratory chain. The formazan can be quantified photometrically and correlates with the metabolic activity and number of viable cells.

The XTT assay (Xenometrix, Allschwil, Switzerland) was performed according to the manufacturer's instructions, after $72 \mathrm{~h}$ incubation with LEV or VPA. The XTT reduction in the cultures was determined after $2 \mathrm{~h}$ incubation by measuring the absorbance at $450 \mathrm{~nm}$ using an absorbance microplate reader ELx808 (BioTek, Winooski, VT, USA). All samples were run in triplicate in the same assay.

\section{Acid phosphatase (AP) assay}

AP is a functional marker of lysosomal metabolism. Enzyme activity is determined by measuring the conversion of $p$-nitrophenylphosphate (pNPP) to $p$-nitrophenolate (pNP) and correlates with viable cell number.
The AP assay (Xenometrix, Allschwil, Switzerland) was performed according to the manufacturer's instructions, after $72 \mathrm{~h}$ incubation with LEV or VPA. The activity of AP in the cultures was determined after $2 \mathrm{~h}$ incubation by measuring the absorbance at $405 \mathrm{~nm}$ using an absorbance microplate reader ELx808 (BioTek, Winooski, VT, USA). All samples were run in triplicate in the same assay.

\section{Lactate dehydrogenase (LDH) assay}

The LDH assay was used to check membrane integrity in cells exposed to LEV or VPA. LDH is rapidly released from damaged cells into cell culture supernatant, where it oxidizes NADH to $\mathrm{NAD}^{+}$. NADH consumption in the supernatant correlates with the amount of LDH released. Cell viability is inversely proportional to the amount of LDH released.

The LDH assay (Xenometrix, Allschwil, Switzerland) was performed according to the manufacturer's instructions, after $72 \mathrm{~h}$ incubation with LEV or VPA. NADH oxidation was determined by measuring the decrease in absorbance at $340 \mathrm{~nm}$ using an absorbance microplate reader ELx808 (BioTek, Winooski, VT, USA). All samples were run in triplicate in the same assay.

\section{Real-time PCR analysis}

Cells were seeded into 96-well culture plates at a density of $2 \times 10^{4}$ cells/well. The next day, the medium was changed and cells were treated with $5 \mathrm{mM}$ VPA or $10 \mathrm{mM} \mathrm{LEV} \mathrm{(concentrations} \mathrm{selected} \mathrm{on} \mathrm{the} \mathrm{basis}$ of alamarBlue, BrdU and cytotoxicity assays) for $24 \mathrm{~h}$. Total RNA isolation and cDNA synthesis was performed using the TaqMan Gene Expression Cellto- $\mathrm{C}_{\mathrm{T}}$ Kit (Applied Biosystems, Carlsbad, CA, USA) according to the manufacturer's protocol. The purity and quantity of the RNA and cDNA were determined by spectrophotometry at optical densities $260 \mathrm{~nm}$ and $280 \mathrm{~nm}$. Amplifications were performed in duplicate using the StepOnePlus system (Applied Biosystems, Carlsbad, CA, USA) and the TaqMan Array Human Cyclins and Cell Cycle Regulation, Fast 96-Well Plate (Cat. No. 4418768), in combination with TaqMan Gene Expression Master Mix (Applied Biosystems, Carlsbad, CA, USA), according to the manufacturer's instructions. PCR was performed in a final volume of $10 \mu$, including $50 \mathrm{ng} /$ reaction cDNA. The PCR conditions were as follows: pre-incubation for $2 \mathrm{~min}$ at 
$50^{\circ} \mathrm{C}$ and $10 \mathrm{~min}$ at $95^{\circ} \mathrm{C}$, amplification for 40 cycles $\left(15 \mathrm{~s}\right.$ at $95^{\circ} \mathrm{C}$ and $1 \mathrm{~min}$ at $\left.60^{\circ} \mathrm{C}\right)$. The relative expression of genes was normalized against the endogenous reference gene, GAPDH.

\section{Statistical analysis}

Each experiment was repeated three times $(n=3)$. All results were expressed as the means \pm standard error of the mean (SEM). Statistical analyses were performed using GraphPad Prism 5 (GraphPad Software Inc., CA, USA). Data were analyzed by one-way analysis of variance, followed by Tukey's Honestly Significant Difference multiple range test. Groups that are significantly different from control are indicated in the figures as: $* \mathrm{p}<0.05, * * \mathrm{p}<0.01, * * * \mathrm{p}<$ 0.001 .

\section{Results}

\section{Determination of long-term cell proliferation using the alamarBlue assay}

In an initial approach to analyze the effects of VPA and LEV, we performed a long-term alamarBlue assay, to determine the concentration-dependent and time-dependent action of LEV and VPA on ovarian cancer cells OVCAR-3. In the control culture, proliferation increased from $14,000 \pm 850$ relative fluorescence units at $24 \mathrm{~h}$ to $22,000 \pm 1,300$ relative fluorescence units at $168 \mathrm{~h}$ of culture.

Cell proliferation at $24 \mathrm{~h}$ of culture was the same for cells exposed to VPA as for control, while a decrease in cell proliferation was noted in cells exposed to VPA con-

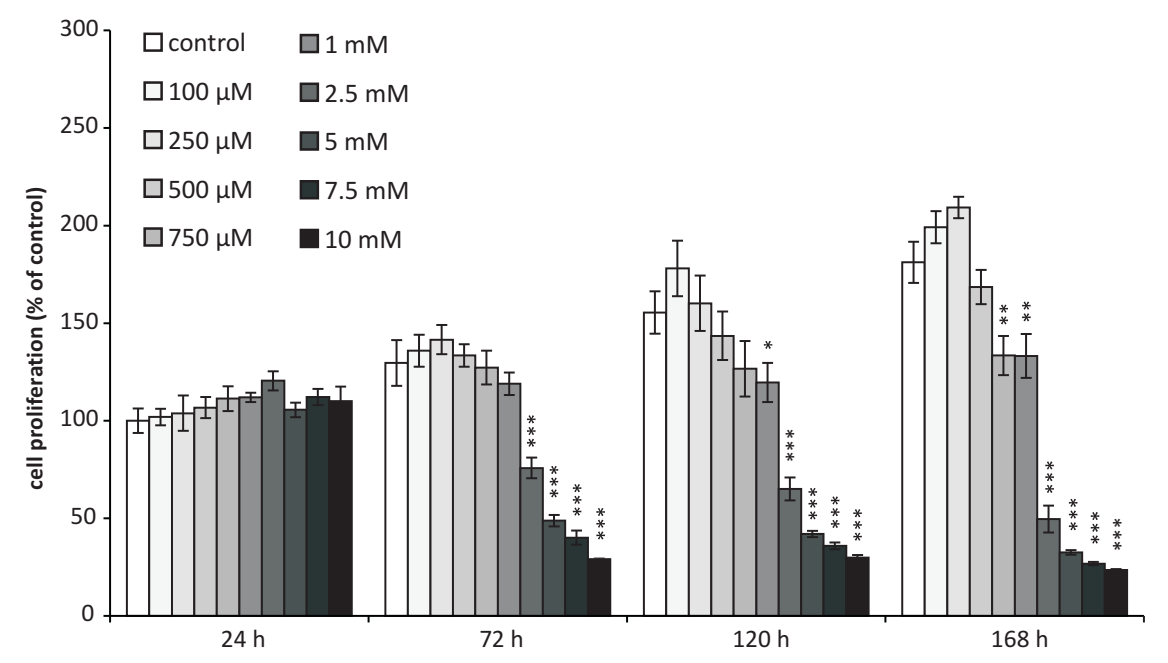

Fig. 1. The effects of valproic acid (VPA) (a) and levetiracetam (LEV) (b) on cell proliferation using the alamarBlue assay. Each point represents the mean \pm SEM of results from three independent experiments, each of which consisted of six replicates per treatment group. All means marked with * $(p<0.05),{ }^{* *}(p<0.01),{ }^{* *}(p<$ $0.001)$ are significantly different from control values

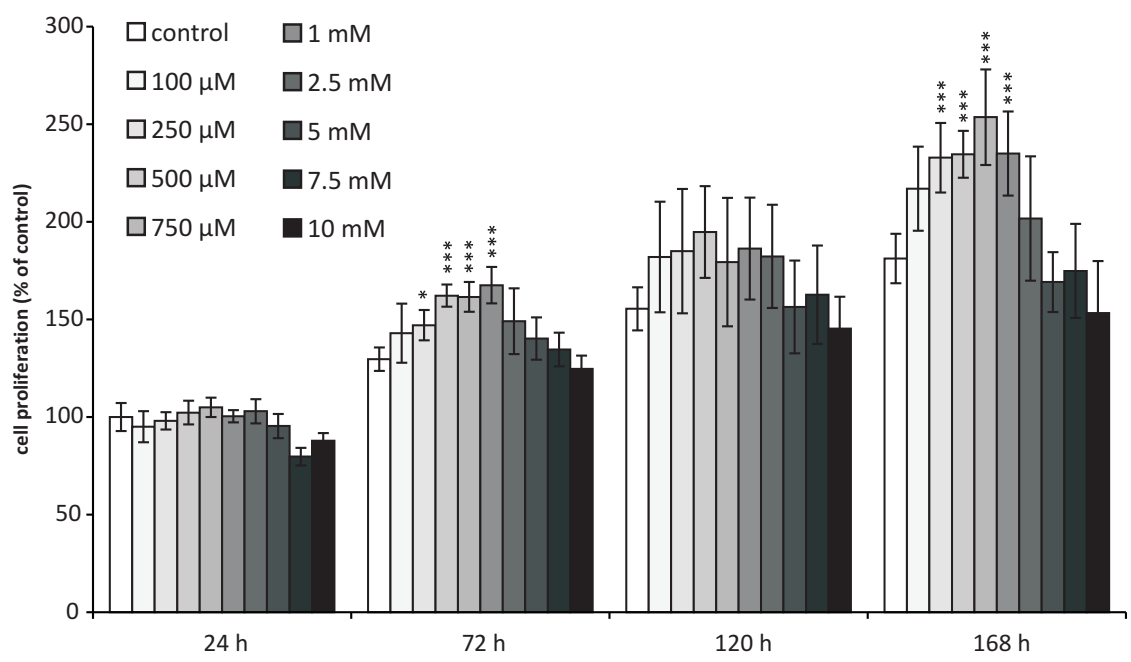


a
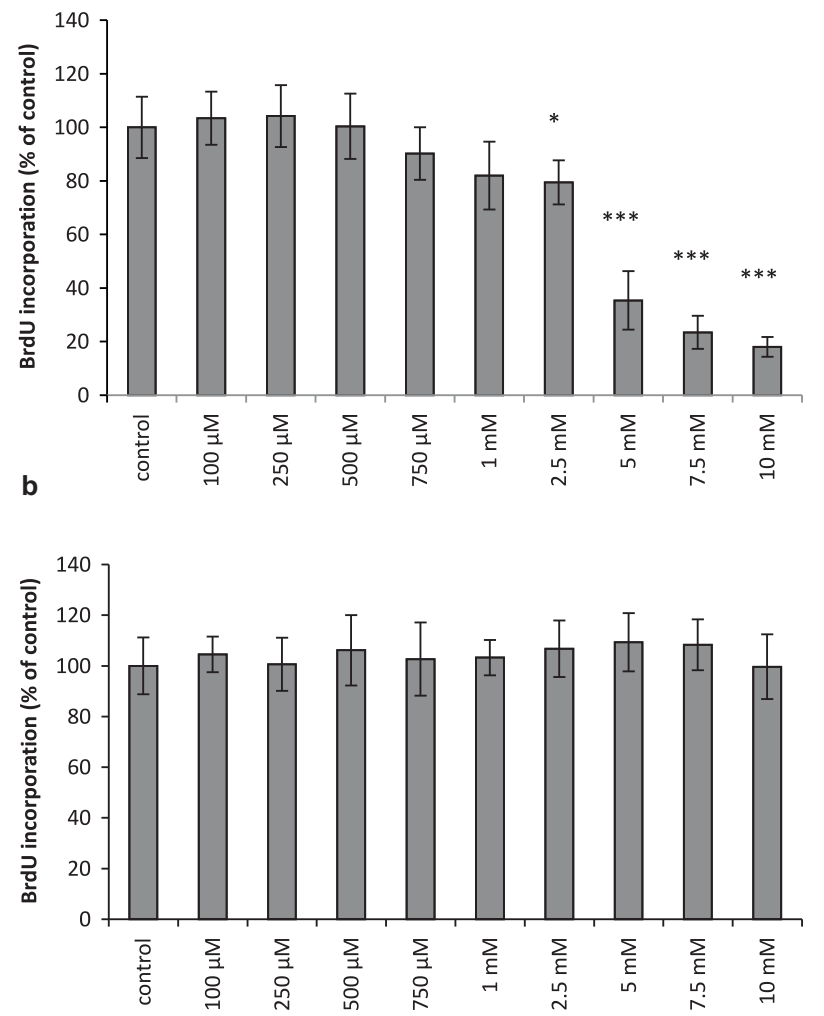

Fig. 2. The effects of valproic acid (VPA) (a) and levetiracetam (LEV) (b) on cell proliferation using the BrdU incorporation assay. Each point represents the mean \pm SEM of results from three independent experiments, each of which consisted of six replicates per treatment group. All means marked with ${ }^{*}(p<0.05),{ }^{* * *}(p<0.001)$ are significantly different from control values

centrations from $2.5 \mathrm{mM}$ at $72 \mathrm{~h}$, from $1 \mathrm{mM}$ at $120 \mathrm{~h}$ and from $750 \mu \mathrm{M}$ at $168 \mathrm{~h}$ of incubation (Fig. 1a).

In LEV-exposed cells, no differences in proliferation from control cells were noted at $24 \mathrm{~h}$ and $120 \mathrm{~h}$ of incubation. However, after $72 \mathrm{~h}$ and $168 \mathrm{~h}$ in culture, cells exposed to LEV concentrations ranging from $250 \mu \mathrm{M}$ to $1 \mathrm{mM}$ demonstrated an increase in proliferation (Fig. 1b).

\section{Determination of cell proliferation using the BrdU incorporation assay}

A significant inhibitory effect of VPA on cell proliferation was noted at concentrations from $2.5 \mathrm{mM}$ to $10 \mathrm{mM}$ (Fig. 2a). Exposure to LEV at all concentrations used did not have any effect compared with the control (Fig. 2b).
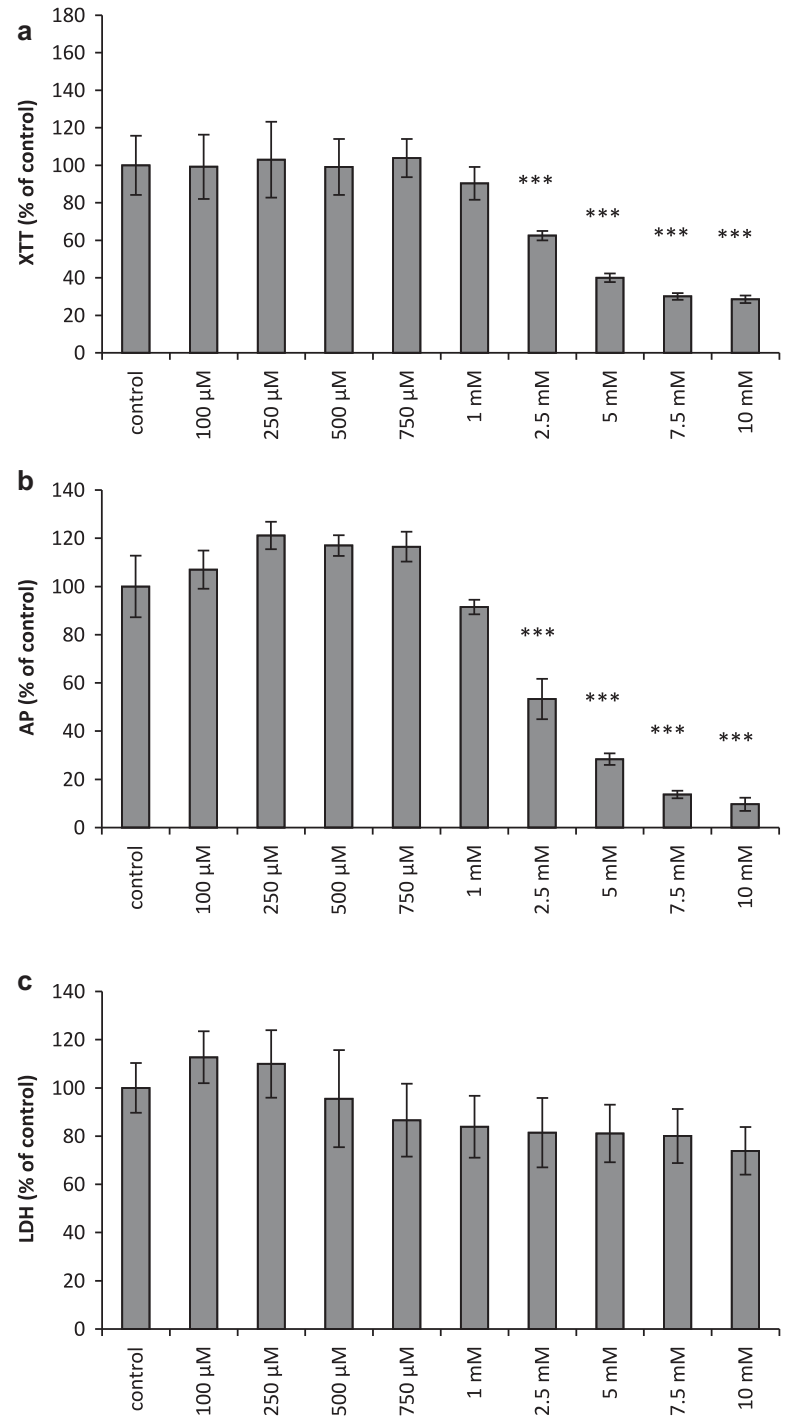

Fig. 3. The cytotoxic effects of valproic acid (VPA) as determined by the XTT assay (a), the AP assay (b) and the LDH assay (c). Each point represents the mean \pm SEM of results from three independent experiments, each of which consisted of three replicates per treatment group. All means marked with ${ }^{\star * *}(p<0.001)$ are significantly different from control values

\section{Determination of cytotoxic effects}

According to the XTT and AP assays results, exposure to VPA at concentrations from $2.5 \mathrm{mM}$ resulted in significant cytotoxic effects (Fig. 3a, 3b), but no significant changes in LDH release into the culture medium (Fig. 3c).

Although exposure to LEV at concentrations from $250 \mu \mathrm{M}$ to $7.5 \mathrm{mM}$ caused an increase reduction of XTT (Fig. 4a), according to the AP assay, cytotoxic effects occurred following exposure to LEV at con- 

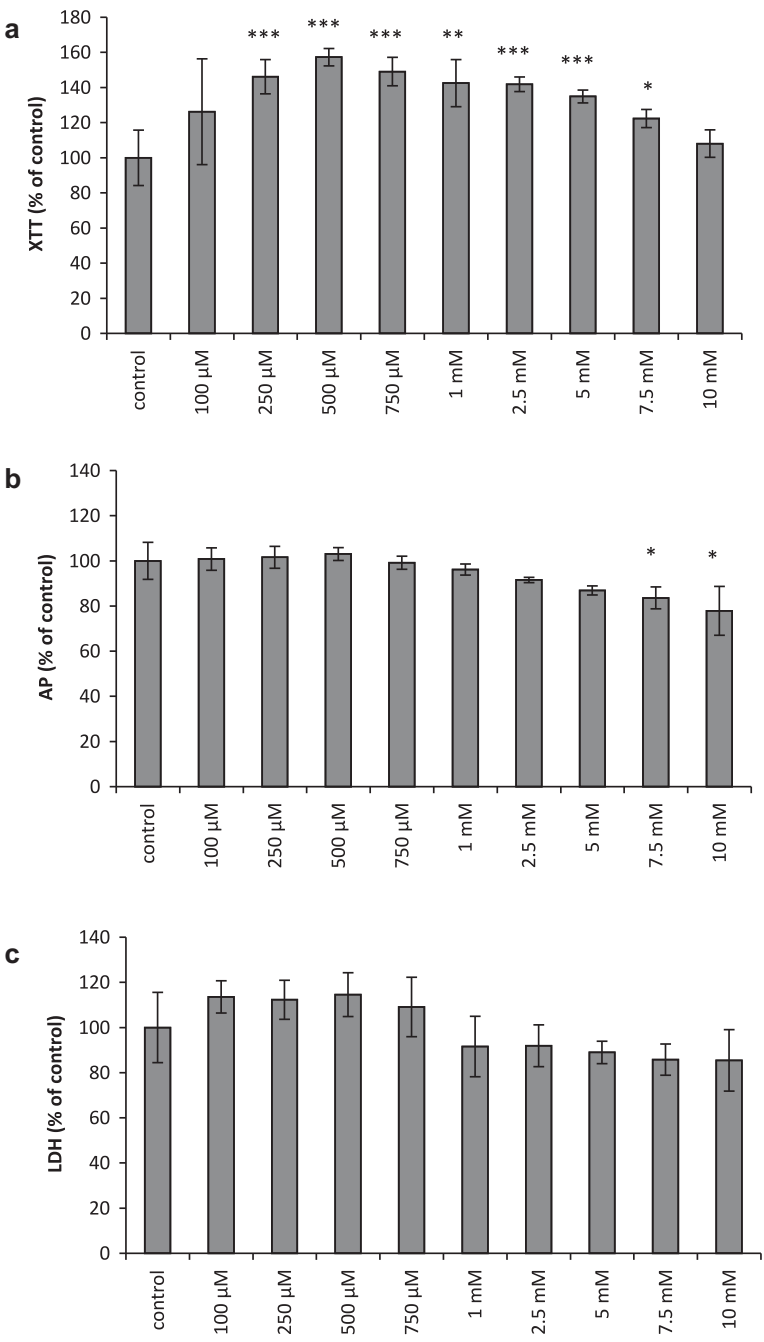

Fig. 4. The cytotoxic effects of levetiracetam (LEV) as determined by the XTT assay (a), the AP assay (b) and the LDH assay (c). Each point represents the mean \pm SEM of results from three independent experiments, each of which consisted of three replicates per treatment group. All means marked with * $(p<0.05),{ }^{* *}(p<0.01),{ }^{* * *}(p<$ $0.001)$ are significantly different from control values

centrations from $7.5 \mathrm{mM}$ (Fig. 4b). As with VPA, LDH levels were not observed to be affected by LEV exposure at all concentrations used (Fig. 4c).

\section{Measurement of expression of cell cycle regulatory genes by real-time PCR analysis}

The relative expression of selected genes involved in cell cycle regulation are described in Table 1. Exposure of cells to VPA resulted in down-regulation of the following genes: CCNA1, CCND3, CCNE1, CCNE2, CCNH (cyclin genes), CDK2, CDK7 (cyclin-dependent kinase genes), CDC25A (CDC25A phosphatase gene), E2F4 (transcription factor E2F4 gene). Parallel up-regulation was observed for: TP53 (tumor protein p53 gene), CDKN1A and $C D K N 2 A$ (cyclin-dependent kinase inhibitors genes). All these genes are involved in arrest of the cell cycle in $\mathrm{G}_{1}$ phase. Exposure to LEV apparently had no effect on the expression of any of these genes involved in cell cycle regulation.

\section{Discussion}

The results from the present study show that exposure to VPA decreases cell proliferation in a concentrationand time-dependent manner, as demonstrated by both alamarBlue and BrdU incorporation assays. These data concur with results published by Takai et al. [31], who also demonstrated growth inhibition of OVCAR-3 cells under the influence of VPA. Additionally, VPA has been shown to interact with standard anticancer drugs, resulting in increased inhibition of ovarian cancer development both in vivo [5] and in vitro [19]. The results from the viability assays in this study demonstrated a significant cytotoxic effect of VPA above $2.5 \mathrm{mM}$, as shown by the XTT and AP assays and no effect on LDH release from cells. The AP assay is used to quantify the lysosomal metabolism of cells in response to pharmaceutical, chemical and environmental compounds, like XTT assay, which is used to measure the mitochondrial metabolism of cells. The results from the XTT and AP assays in combination clearly suggest that VPA causes cytotoxic effects in OVCAR-3 cells.

Following the demonstration that VPA decreased OVCAR-3 cells proliferation and acts as cytotoxic drug, it was pertinent to examine the underlying mechanisms that cause this anti-proliferative effect. The investigation of expression of genes involved in cell cycle regulation showed that VPA had most affect on the expression of CDKN1A and CDKN2A genes, which encode the cyclin-dependent kinase inhibitor p21 and cyclin-dependent kinase inhibitor p16, respectively, and are primarily linked to $\mathrm{G}_{1}$-phase regulation. It is noteworthy that regulators of cell cycle machinery are frequently altered in human cancers and can be more sensitive to cyclin-dependent kinases' inhibition [28]. Moreover, altered expression of multiple genes and proteins involved in cell cycle regulation (especially p21 and p16), has previously 
Tab. 1. Relative alterations in expression of selected genes involved in cell cycle regulation in OVCAR-3 cells exposed to $5 \mathrm{mM}$ VPA or $10 \mathrm{mM}$ LEV for 24 h. All values marked with * $(p<0.05)$, ${ }^{* *}(p<0.01),{ }^{* *}(p<0.001)$ are significantly different from control

\begin{tabular}{|c|c|c|c|c|}
\hline \multirow[t]{2}{*}{ Assay ID } & \multirow[t]{2}{*}{ Description } & \multirow{2}{*}{$\begin{array}{l}\text { Gene symbol } \\
\text { (Alias) }\end{array}$} & \multicolumn{2}{|c|}{ Fold change } \\
\hline & & & VPA & LEV \\
\hline \multicolumn{5}{|c|}{ Cell cycle progression activators } \\
\hline Hs00171105_m1 & Cyclin-A1 & CCNA1 & $0.77^{\star}$ & 1.08 \\
\hline Hs00153138_m1 & Cyclin-A2 & CCNA2 & 1.05 & 1.05 \\
\hline Hs99999188_m1 & Cyclin-B1 & CCNB1 & 1.05 & 1.14 \\
\hline Hs00270424_m1 & Cyclin-B2 & CCNB2 & 1.02 & 1.05 \\
\hline Hs00765553_m1 & Cyclin-D1 & CCND1 & 1.01 & 1.01 \\
\hline Hs00236949_m1 & Cyclin-D3 & CCND3 & $0.70^{\star *}$ & 1.04 \\
\hline Hs01026536_m1 & Cyclin-E1 & CCNE1 & $0.77^{\star}$ & 1.05 \\
\hline Hs00372959_m1 & Cyclin-E2 & CCNE2 & $0.85^{\star}$ & 0.93 \\
\hline Hs00236923_m1 & Cyclin-H & $\mathrm{CCNH}$ & $0.75^{\star}$ & 1.00 \\
\hline Hs00364293_m1 & Cyclin-dependent kinase 1 & CDK1 (CDC2) & 0.86 & 1.01 \\
\hline Hs01548894_m1 & Cyclin-dependent kinase 2 & CDK2 & $0.72^{*}$ & 0.90 \\
\hline Hs00175935_m1 & Cyclin-dependent kinase 4 & CDK4 & 1.04 & 1.07 \\
\hline Hs01026372_m1 & Cyclin-dependent kinase 6 & CDK6 & 1.00 & 1.00 \\
\hline Hs00361486_m1 & Cyclin-dependent kinase 7 & CDK7 & $0.85^{\star}$ & 1.00 \\
\hline Hs00947994_m1 & Cell division cycle 25 homolog A & CDC25A & $0.70^{* *}$ & 0.91 \\
\hline Hs01078066_m1 & Retinoblastoma-associated protein (pRb) & $R B 1(p R b)$ & 0.90 & 1.03 \\
\hline Hs00153451_m1 & Transcription factor E2F1 & E2F1 & 0.95 & 1.03 \\
\hline Hs00231667_m1 & Transcription factor E2F2 & E2F2 & 0.95 & 1.05 \\
\hline Hs00605457_m1 & Transcription factor E2F3 & E2F3 & 0.99 & 1.09 \\
\hline Hs00608098_m1 & Transcription factor E2F4 & E2F4 & $0.77^{\star}$ & 1.03 \\
\hline \multicolumn{5}{|c|}{ Cell cycle progression inhibitors } \\
\hline Hs01034249_m1 & Tumor protein p53 & TP53 & $1.33^{\star \star}$ & 1.02 \\
\hline Hs01112307_m1 & Ataxia telangiectasia mutated & ATM & 0.87 & 0.95 \\
\hline Hs00354807_m1 & Ataxia telangiectasia and Rad3 related & ATR & 0.86 & 0.86 \\
\hline Hs00355782_m1 & Cyclin-dependent kinase inhibitor 1A (p21) & CDKN1A & $1.63^{\star \star *}$ & 0.92 \\
\hline Hs00153277_m1 & Cyclin-dependent kinase inhibitor 1B (p27) & CDKN1B & 0.88 & 0.86 \\
\hline Hs00923894_m1 & Cyclin-dependent kinase inhibitor 2A (p16) & CDKN2A & $2.13^{* * *}$ & 1.10 \\
\hline Hs00176227_m1 & Cyclin-dependent kinase inhibitor 2C (p18) & CDKN2C & 0.91 & 1.01 \\
\hline Hs00176481_m1 & Cyclin-dependent kinase inhibitor 2D (p19) & CDKN2D & 0.86 & 0.94 \\
\hline
\end{tabular}

been reported in cancer cells exposed to VPA treatment $[6,7,9,10,16,17,22,30-32,34]$. In addition, we showed that VPA stimulated TP53 transcription. Tumor protein p53 is known to be induced as a result of DNA fragmentation; activation of $\mathrm{p} 53$ results in $\mathrm{G}_{1}$ arrest by inducing $\mathrm{p} 21$, followed by an inhibition of cyclin/Cdk complex [18]. Marked inhibition in expression of other genes involved in cell cycle regulation, which encode both cyclins (cyclin A, cyclin E, cyclin $\mathrm{D}$, cyclin $\mathrm{H}$ ) and cycline-dependent kinases (Cdk2 and Cdk7), was also observed. These proteins form cyclin/Cdk complexes and regulate progression of the cell cycle through specific checkpoints [20]. Cyclin $\mathrm{E} / \mathrm{Cdk} 2$ is required for S phase entry, cyclin $\mathrm{A} / \mathrm{Cdk} 2$ for $\mathrm{S}$ phase progression and D cyclins, associated with $\mathrm{Cdk} 4$ and $\mathrm{Cdk} 6$, are required for progression of cells through $\mathrm{G}_{1}$ into $\mathrm{S}$ phase. Furthermore, cyclin $\mathrm{H} / \mathrm{Cdk} 7$ complex and phosphatase Cdc25A are 
responsible for activation of cyclin-dependent kinases, which is why suppressed transcription of these genes results in additional deactivation of cyclin/ $\mathrm{Cdk}$ complexes. All these findings suggest that cells exposed to VPA may have their cycle arrested in $\mathrm{G}_{1}$ phase. Our results from the BrdU incorporation assay, demonstrating a dramatic decrease in DNA synthesis under the influence of higher concentrationss of VPA, support this theory. Previously published data on the effect of VPA on the OVCAR-3 cell line, showing an accumulation in the $G_{0} / G_{1}$ phase of the cell cycle and a concomitant decrease in the proportion of cells in $\mathrm{S}$ phase [31], provide further support.

Part of the experiments concerning action of LEV on cell proliferation and viability, demonstrated that LEV did not affect cell proliferation as determined by the BrdU incorporation assay. This observation is in accordance with data of Paulson et al. [26] demonstrated that LEV did not affect the number of BrdUpositive cells in rat hippocampus. Surprisingly, exposure to LEV increased cell proliferation measured by alamarBlue assay and activity of mitochondrial enzymes, as measured with the XTT assay. It could be explained by the fact that both assays determine total cell number by detection of cellular (mitochondrial) metabolic activity. Additionally, a cytotoxic effect of LEV (AP assay) was noted only at higher concentrations and no change in LDH level was observed. AP is a functional marker of the lysosomal compartment [14] and the lysosomal enzymes are known to initiate cell death [12], but it is also suggested that activation of lysosomal enzymes is specific for tumor regression, but do not affect proliferation [1]. Although the effects of VPA on cancer growth are widely known, only limited data on the effect of LEV on cellular proliferation are available. Whilst data indicating that LEV has a very positive effect on brain tumorassociated seizures have been published, whether the development of cancer per se is affected by LEV is unknown [21, 23-25, 29, 35]. Indeed, it has been demonstrated that LEV does not interact with chemotherapies used in the treatment of brain tumors [27].

In contrast to VPA, the expression of cell cycle genes appeared to be unaffected by exposure to LEV. Data published by Hassel et al. [13] reported regionspecific gene expression as a result of LEV treatment, but as LEV-induced regional changes in gene expression were not closely associated with the distribution of known LEV binding sites (such as synaptic vesicle protein SV2A), no plausible explanation could be provided. Additionally, other research has shown that LEV does not modify gene expression in nonepileptic rat brain [11], nor in brains of non-epileptic newborn mice [33].

Taken together, these results suggest that LEV disrupts cells metabolism, but this has no effect on cell proliferation and cell cycle regulating genes expression.

In conclusion, the results of this preliminary study, suggest that VPA, but not LEV, may have potential as an anticancer drug for human ovarian cancer treatment due to its cytotoxic and cytostatic activities. However, further studies, based on apoptotic mechanisms, are essential to confirm this suggestion.

\section{Acknowledgment:}

This study was supported by grants from Department of Neurology, Oslo University Hospital - Rikshospitalet, Oslo, Norway and by K/ZDS/001715/2010, Poland.

This publication includes part of the data presented in Patrycja Kwiecińska's PhD dissertation.

\section{References:}

1. Anton E, Brandes D: Lysosomes in mice mammary tumors treated with cyclophosphamide. Distribution related to course of disease. Cancer, 1968, 21, 483-500.

2. Blaheta RA, Cinatl J Jr: Anti-tumor mechanisms of valproate: a novel role for an old drug. Med Res Rev, 2002, 22, 492-511.

3. Blaheta RA, Michaelis M, Driever PH, Cinatl J Jr: Evolving anticancer drug valproic acid: insights into the mechanism and clinical studies. Med Res Rev, 2005, 25, 383-397.

4. Bobustuc GC, Baker CH, Limaye A, Jenkins WD, Pearl G, Avgeropoulos NG, Konduri SD: Levetiracetam enhances p53-mediated MGMT inhibition and sensitizes glioblastoma cells to temozolomide. NeuroOncol, 2010, 12, 917-927.

5. Candelaria M, Gallardo-Rincón D, Arce C, Cetina L, Aguilar-Ponce JL, Arrieta O, González-Fierro A et al.: A phase II study of epigenetic therapy with hydralazine and magnesium valproate to overcome chemotherapy resistance in refractory solid tumors. Ann Oncol, 2007, 18, 1529-1538.

6. Catalano MG, Fortunati N, Pugliese M, Costantino L, Poli R, Bosco O, Boccuzzi G: Valproic acid induces apoptosis and cell cycle arrest in poorly differentiated thyroid cancer cells. J Clin Endocrinol Metab, 2005, 90, 1383-1389.

7. Cheng YC, Lin H, Huang MJ, Chow JM, Lin S, Liu HE: Downregulation of c-Myc is critical for valproic acidinduced growth arrest and myeloid differentiation of acute myeloid leukemia. Leuk Res, 2007, 31, 1403-1411. 
8. Crepeau AZ, Treiman DM: Levetiracetam: a comprehensive review. Expert Rev Neurother, 2010, 10, 159-171.

9. Fortunati N, Bertino S, Costantino L, Bosco O, Vercellinatto I, Catalano MG, Boccuzzi G: Valproic acid is a selective antiproliferative agent in estrogen-sensitive breast cancer cells. Cancer Lett, 2008, 259, 156-164.

10. Greenblatt DY, Vaccaro AM, Jaskula-Sztul R, Ning L, Haymart M, Kunnimalaiyaan M, Chen H: Valproic acid activates notch-1 signaling and regulates the neuroendocrine phenotype in carcinoid cancer cells. Oncologist, 2007, 12, 942-951.

11. Gu J, Lynch BA, Anderson D, Klitgaard H, Lu S, Elashoff M, Ebert U et al.: The antiepileptic drug levetiracetam selectively modifies kindling-induced alterations in gene expression in the temporal lobe of rats. Eur J Neurosci, 2004, 19, 334-345.

12. Halaby R: Lysosomal enzyme-induced cell death in MCF7 and mammary gland cells. Breast Cancer Res, 2002, 4, EO01.

13. Hassel B, Taubřll E, Shaw R, Gjerstad L, Dingledine R: Region-specific changes in gene expression in rat brain after chronic treatment with levetiracetam or phenytoin Epilepsia, 2010, 51, 1714-1720.

14. Hønsi TG, Stenersen J: Activity and localisation of the lysosomal marker enzymes acid phosphatase, $\mathrm{N}$-acetyl$\beta$-D-glucosaminidase, and $\beta$-galactosidase in the earthworms Eisenia fetida and E. veneta. Comp Biochem Physiol B Biochem Mol Biol, 2000, 125, 429-437.

15. Jemal A, Siegel R, Ward E, Hao Y, Xu J, Thun MJ: Cancer statistics, 2009. CA Cancer J Clin, 2009, 59, 225-249.

16. Kaiser M, Zavrski I, Sterz J, Jakob C, Fleissner C, Kloetzel PM, Sezer O, Heider U: The effects of the histone deacetylase inhibitor valproic acid on cell cycle, growth suppression and apoptosis in multiple myeloma. Haematologica, 2006, 91, 248-251.

17. Li XN, Shu Q, Su JM, Perlaky L, Blaney SM, Lau CC: Valproic acid induces growth arrest, apoptosis, and senescence in medulloblastomas by increasing histone hyperacetylation and regulating expression of $\mathrm{p} 21 \mathrm{Cip} 1$, CDK4, and CMYC. Mol Cancer Ther, 2005, 4, 1912-1922.

18. Li Y, Jenkins CW, Nichols MA, Xiong Y: Cell cycle expression and $\mathrm{p} 53$ regulation of the cyclin-dependent kinase inhibitor p21. Oncogene, 1994, 9, 2261-2268.

19. Lin CT, Lai HC, Lee HY, Lin WH, Chang CC, Chu TY, Lin YW et al.: Valproic acid resensitizes cisplatinresistant ovarian cancer cells. Cancer Sci, 2008, 99, $1218-1226$

20. Malumbres M, Barbacid M: Mammalian cyclin-dependent kinases. Trends Biochem Sci, 2005, 30, 630-641.

21. Maschio M, Albani F, Baruzzi A, Zarabla A, Dinapoli L, Pace A, Pompili A et al.: Levetiracetam therapy in patients with brain tumour and epilepsy. J Neurooncol, 2006, 80, 97-100.

22. Neri P, Tagliaferri P, Di Martino MT, Calimeri T, Amodio N, Bulotta A, Ventura $\mathrm{M}$ et al.: In vivo anti-myeloma activity and modulation of gene expression profile in- duced by valproic acid, a histone deacetylase inhibitor. Br J Haematol, 2008, 143, 520-531.

23. Newton HB, Dalton J, Goldlust S, Pearl D: Retrospective analysis of the efficacy and tolerability of levetiracetam in patients with metastatic brain tumors. J Neurooncol 2007, 84, 293-296.

24. Newton HB, Goldlust SA, Pearl D: Retrospective analysis of the efficacy and tolerability of levetiracetam in brain tumor patients. J Neurooncol, 2006, 78, 99-102.

25. Partap S, Fisher PG: Levetiracetam for seizures in children with brain tumors and other cancers. Pediatr Blood Cancer, 2009, 52, 288-289.

26. Paulson L, Persson A, Vonck K, Van Dycke A, Kuhn HG, Boon P, Ben-Menachem E, Raedt R: Effect of levetiracetam on hippocampal protein expression and cell proliferation in rats. Epilepsy Res, 2010, 90, 110-120.

27. Ruggiero A, Rizzo D, Mastrangelo S, Battaglia D, Attinà G, Riccardi R: Interactions between antiepileptic and chemotherapeutic drugs in children with brain tumors: is it time to change treatment? Pediatr Blood Cancer, 2010, 54, 193-198.

28. Sherr CJ: Cancer cell cycles. Science, 1996, 274, 1672-1677.

29. Szaflarski JP, Meckler JM, Szaflarski M, Shutter LA, Privitera MD, Yates SL: Levetiracetam use in critically ill patients. Neurocrit Care, 2007, 7, 140-147.

30. Takai N, Desmond JC, Kumagai T, Gui D, Said JW, Whittaker S, Miyakawa I, Koeffler HP: Histone deacetylase inhibitors have a profound antigrowth activity in endometrial cancer cells. Clin Cancer Res, 2004, 10, 1141-1149.

31. Takai N, Kawamata N, Gui D, Said JW, Miyakawa I, Koeffler HP: Human ovarian carcinoma cells: histone deacetylase inhibitors exhibit antiproliferative activity and potently induce apoptosis. Cancer, 2004, 101, 2760-2770.

32. Travaglini L, Vian L, Billi M, Grignani F, Nervi C: Epigenetic reprogramming of breast cancer cells by valproic acid occurs regardless of estrogen receptor status. Int J Biochem Cell Biol, 2009, 41, 225-234.

33. Trollmann R, Schneider J, Keller S, Strasser K, Wenzel D, Rascher W, Ogunshola OO, Gassmann M: HIF-1-regulated vasoactive systems are differentially involved in acute hypoxic stress responses of the developing brain of newborn mice and are not affected by levetiracetam. Brain Res, 2008, 1199, 27-36.

34. Valentini A, Gravina P, Federici G, Bernardini S:Valproic acid induces apoptosis, p16INK4A upregulation and sensitization to chemotherapy in human melanoma cells. Cancer Biol Ther, 2007, 6, 185-191.

35. Wagner GL, Wilms EB, Van Donselaar CA, Vecht ChJ: Levetiracetam: preliminary experience in patients with primary brain tumours. Seizure, 2003, 12, 585-586.

Received: April 13, 2011; in the revised form and accepted: September 23, 2011. 